\title{
EDUCACIÓN DE LA EXPRESIÓN DE LA SEXUALIDAD HUMANA
}

\author{
Sonia Carballo Vargas
}

El amor es lo que hace que las relaciones interpersonales sean verdaderamente humanas

Recibido 19-III-2002
Resumen: En el presente artículo se parte de que la sexualidad humana es una dimensión de la personalidad impregnada desde la concepción por las mismas características biosicosociales y espirituales de la persona. Se expresa en la relación de ella consigo misma y en la convivencia con los otros a través de los vínculos emocionales, del papel sexual, de la respuesta sexual y el erotismo, y de la reproducción. Así mismo se plantea que educar a las personas en la expresión de la sexualidad es un proceso desafiante y placentero, dinámico y nunca acabado, que permite construir y reconstruir sistemáticamente actitudes, valores, sentimientos, intereses, conocimientos y formas de comportamiento sanos racional y emocionalmente. Por tanto se afirma que la educación de la expresión de la sexualidad se da durante toda la vida para aprender a convivir juntos, para aprender a conocer, para aprender a hacer y para aprender a ser, en un marco de derechos humanos, con el objetivo de construir formas inteligentes cognitiva y emocionalmente que lleven al disfrute pleno y voluntario de la sexualidad.

\section{Introducción}

La sexualidad humana es una dimensión de la personalidad impregnada desde la concepción por las mismas características biopsicosociales y espirituales de la persona. Nace y evoluciona con ella y se expresa en la relación de la persona consigo misma y en la convivencia con las otras personas a través de los vínculos emocionales, del papel sexual, de la respuesta sexual, del erotismo y de la reproducción.

Las estructuras anatómicas y el funcionamiento fisiológico del sistema endocrino, del sistema nervioso, de los órganos genitales y las zonas erógenas del cuerpo humano se retroalimentan unas a otras para formar la base biológica de la expresión sexual humana. La armonía con que funcionan normalmente estas estructuras, fortalece la organización biológica de la reproducción, del placer y el erotismo, de la respuesta sexual, de los vínculos emocionales entre los seres humanos y del papel sexual.

Las habilidades cognitivas y emocionales de la persona, su organización y funcionamiento biológico, interaccionan desde la concepción con el ambiente sociocultural en el cual vive y le permiten construir patrones de comportamiento único para expresar su sexualidad en cada fase de su desarrollo, en cada época histórica y en cada sociedad en particular. 
Educar a las personas en la expresión de la sexualidad es un proceso arduo y placentero, dinámico y nunca acabado, que contribuye a que la persona se acepte a sí misma en la diaria convivencia humana, que acepte y respete a los otros seres humanos y a que se ajuste, responsablemente a los avances y cambios de los tiempos. Es un proceso que permite construir y analizar sistemáticamente actitudes, valores, sentimientos, intereses, conocimientos y formas de expresar la sexualidad.

La educación de la expresión de la sexualidad implica: comprender a la persona como un ser sexuado, y comprender que la sexualidad es parte integral de su personalidad. Implica también, investigar y analizar los avances científicos que contribuyen día a día a la evolución histórica de la sexualidad, así como los acontecimientos sociales que dejan huella en la expresión de la misma. Esta educación debe centrarse en los intereses y necesidades del ser humano, en el contexto sociocultural y espiritual y en la época histórica que se vive.

A continuación se expresan una serie de planteamientos para orientar la educación de la expresión de la sexualidad humana. Sin pretender agotar la temática, se puntualizan conceptos para análisis, diálogo y discusión, con el objetivo de incentivar la construcción de estrategias para expresar la sexualidad y de fortalecer habilidades intelectuales y emocionales para una educación permanente en sexualidad humana.

\section{Vínculos emocionales}

Desde antes de la concepción, las expectativas de los progenitores constituyen un acto de amor (aceptación) o de rechazo hacia el niño o la niña. El crecimiento de la persona en el útero es un proceso de extraordinaria regularidad y predicción, controlado por un patrón genético que ordena el crecimiento de sus partes, de modo que cada una de ellas tiene su período de maduración, hasta que el conjunto emerge como un todo que funciona.

A partir de su nacimiento la persona continúa su desarrollo evolutivo a través de una secuencia de fases ordenadas, mutuamente dependientes, predeterminadas por la disposición de su organismo para ser impulsado a interactuar con un radio social más amplio, empezando con una oscura imagen de la figura materna y terminando con una representación de la humanidad. Este nuevo proceso, se inicia con una serie de crisis existenciales cuya resolución conlleva el fortalecimiento o debilitamiento de diversos vínculos emocionales.

Erik Erikson (1970) conforma el desarrollo psicosexual humano en ocho crisis existenciales. Para este neofreudiano, la primera de estas crisis es la de confianza contra desconfianza, y se presenta en la etapa oral sensorial comprendida más o menos entre el nacimiento y el año y medio de edad. En el niño y en la niña el desarrollo de los vínculos emocionales de confianza o de desconfianza con el ambiente que los rodea se fundamentan ahora, en su intensa dependencia de sus progenitores, en especial de la calidad de sus relaciones emocionales con su madre. Si este lazo interpersonal es de satisfacción y seguridad creará en él y en ella un estado general básico de salud psicológica, de confianza en sí mismos y en su ambiente, permitiéndoles una mayor tolerancia a la frustración y más esperanza en la humanidad.

La segunda crisis por resolver en el ser humano, es la de autonomía contra vergüenza y duda, en la fase freudiana analuretral. El niño y la niña entre el año y medio y los tres años de edad, pueden desplazarse por sí mismos en un espacio más amplio, gracias a los avances en el proceso de su maduración psicomotriz. También, su pensamiento lógico les permite adquirir más conciencia del dominio que pueden ejercer sobre sí mismos y el ambiente. Los vínculos emocionales, fortalecidos por la 
confianza en sí mismos y en la sociedad, llevan al niño y a la niña a darle un valor enorme al aprendizaje, al ejercicio de su voluntad y a la autonomía de su madre o de su padre, en diversas áreas de su actividad. No obstante, al mismo tiempo comprenden que sus limitaciones presentes los impulsan a prolongar su dependencia de los adultos y, entonces, dudan de sus propias potencialidades para buscar y lograr más autonomía, de modo que si no reciben ayuda de los mayores y más fuertes, desarrollarán sentimientos de vergüenza de sí mismo o de sí misma.

En la fase freudiana locomotriz-genital, se presenta la tercera crisis existencial: iniciativa contra culpa. Entre los tres y seis años de edad el niño y la niña amplían su capacidad de desplazamiento, juego y aprendizaje debido a que tienen más control de su sistema muscular, dominio del lenguaje y pensamiento lógico preoperacional. Son niños y niñas exuberantes, llenos de vitalidad, imaginación, curiosidad, deseos de conocer su propio cuerpo y de experimentar con sus nuevas capacidades, que emprenden muchas tareas y afrontan cambios importantes en los vínculos emocionales que establecen en las relaciones interpersonales. Estos niños tienen que aprender a desarrollar un sentido de libertad, autocontrol, equilibrio y mayor madurez compartiendo obligaciones y actividades en un grupo social que ahora es más extenso.

Durante los años escolares, de los seis a los once años de edad, más o menos, el niño y la niña aprenden destrezas propias de su cultura. Es una época de relativa "latencia" en el desarrollo físico y sexual, con un rápido desarrollo de habilidades intelectuales y emocionales. La cuarta crisis existencial que necesita resolver ahora, es industria contra inferioridad. En esta fase escolar, la productividad y búsqueda de éxito adquieren importancia. Los vínculos emocionales que el niño y la niña establecen los llevan a producir para merecer reconocimiento por sus propias iniciativas, diligencias y atención sostenida. Tratan de aprender haciendo, aplicando sus nuevas destrezas a sus tareas, esforzándose por dominar las herramientas utilizadas por los adultos significativos de su cultura; esto les permite disfrutar, crecer y formarse un concepto positivo de sí mismos como personas.

Alrededor de los doce y veinte años, el joven ser humano entra a vivir la quinta crisis existencial, que Erikson (1970) llama identidad contra difusión de identidad. La rapidez del crecimiento corporal y la madurez genital señala la transformación del niño y de la niña en jóvenes, cuya tarea principal es el logro de su identidad como persona ¿Quién soy? Este proceso es un esfuerzo por integrar, en grado suficiente, las identificaciones anteriores parciales y variadas (identificación con cada uno de sus progenitores) con sus tendencias biológicas, sus potencialidades y sus funciones. Para la persona, este darse sentido a sí misma es un proceso vital y saludable que contribuye a la interacción y fortalecimiento del "yo", que le permite construir su propio estilo de vida y establecer vínculos emocionales estrechos con sus iguales para ser aceptada, amada y respetada por lo que ella es. El peligro sería la difusión de la identidad, algunas veces inevitable en este período. Cuando esta difusión de la identidad se basa en una marcada duda en cuanto a la propia identidad sexual, son frecuentes la ansiedad, depresión, confusión, un sentido de alienación y de soledad.

El crecimiento y desarrollo de las personas en estas edades puede representarse por medio de un modelo muy flexible de aprendizaje y ajustes, integrados en seis tareas evolutivas de realización paralela, o sea, no excluyentes entre sí: aceptar y aprovechar el cuerpo, madurar los vínculos emocionales con sus iguales, lograr autonomía de los adultos significativos, elegir y prepararse en una vocación, vivir relaciones de 
noviazgo y reflexionar sobre el matrimonio, lograr su identidad personal, una escala de valores y una filosofía de la vida (Havighurst, 1969).

Logradas esas tareas evolutivas surge el adulto y la adulta joven, preparados para establecer vínculos emocionales consigo y con los otros seres humanos sin dejar de ser ellos y ellas mismas. Este nuevo patrón de vínculos afectivos requiere de una intimidad, probablemente no experimentada en los estados anteriores del desarrollo porque implica igualdad, aceptación de intereses y necesidades biológicas, psicológicas, sociales y espirituales integradas plenamente, que les permitan resolver satisfactoriamente la sexta crisis existencial de la intimidad contra el aislamiento.

La expresión de la sexualidad, mediante los vínculos emocionales, requiere ahora que la persona integre amor y trabajo a su cotidianeidad y que con sus habilidades emocionales de autoconocimiento, automotivación, autocontrol y empatía, asuma compromisos y cumpla con responsabilidades en las relaciones interpersonales. El evitar la intimidad, conduce a la persona joven a un profundo sentido de aislamiento y a un encerrarse en sí misma, es decir, a una incapacidad para arriesgar la identidad propia, para amar sin comprometer su identidad.

El adulto y la adulta joven, ciertamente deben estar bien informados y formados para disfrutar de la expresión de su propia sexualidad y asumir las obligaciones y derechos derivados del trascender a otros sin perder su identidad, aceptándolos como personas únicas e irrepetibles, independientemente de su sexo, a través de la construcción de vínculos emocionales.

La sétima crisis existencial: generatividad contra aislamiento, impregna los vínculos emocionales que la persona adulta establece en sus relaciones interpersonales. Desde esta dimensión, la persona tiene otras virtudes básicas que adquirir: productividad y cuidado. La creación de vínculos emocionales basados en la confianza y en la intimidad incluye la posibilidad de conservar la convivencia en pareja y el trabajo seleccionado. Una unión conyugal sana es el fundamento para asegurar el desarrollo satisfactorio de una nueva generación. La preocupación por esta última, plantea vínculos emocionales de otro nivel: preocupación que posee la generación más vieja con respecto a la nueva generación. La persona adulta enriquece su vida produciendo, conservando y transmitiendo las esperanzas, virtudes y sabidurías acumuladas. La generatividad es, entonces, la responsabilidad del adulto de afirmar y orientar a la nueva generación, contribuyendo a la construcción de un mundo mejor para la humanidad, asegurándole la confianza básica de la primera crisis existencial. Si bien el concepto de generatividad incluye la productividad y la creatividad ninguna de las dos puede reemplazarla. La capacidad de entregarse, mediante vínculos emocionales, conlleva una expansión gradual de los intereses del yo y un vuelco hacia aquello que está generándose. Cuando tal enriquecimiento falta, se produce una regresión a una necesidad obsesiva de seudointimidad, a menudo, acompañada de sentimientos de estancamiento y empobrecimiento.

La persona, al llegar a ser adulto mayor expresa su sexualidad por los vínculos emocionales, contextualizados dentro de la crisis existencial: integridad contra desesperación. El envejecimiento es un proceso involutivo, natural, de cambios paulatinos que se extiende a lo largo de casi toda la vida. Se espera que en la vejez, la persona, logre integrar el concepto de sí misma, comprenda y acepte que su propio ciclo de vida y el de las personas que han llegado a ser significativas para ella son hechos únicos e irrepetibles y que inevitablemente se debe afrontar la muerte con sabiduría y renunciación.

Existen variaciones individuales en las transformaciones del proceso involutivo 
de envejecer, pero en la época actual, la mayoría de las personas adultas mantienen sus habilidades intelectuales y emocionales, están conscientes y disfrutan del ambiente reflejando su autorrealización y expresando su sexualidad, a través de los vínculos emocionales con los demás.

\section{Papeles sexuales}

A lo largo de la historia, hombres y mujeres o feminidades y masculinidades, expresan su sexualidad asumiendo un papel asignado socialmente, que estereotipa comportamientos, ahondando las desigualdades de derechos entre ambos.

En los ámbitos económico, político, educativo, laboral y en la sociedad en general se empezó a tomar conciencia de la injusticia de esta desigualdad y es alrededor de los años sesenta, que surgen movimientos de liberación femenina que luchan por poner fin a esa situación social.

Los valores que orientaban los vínculos emocionales entre hombre y mujer establecían relaciones de pareja basados en el dominio, la hostilidad y la incomprensión del hombre sobre la mujer. La mujer y el hombre inmersos en un modelo de familia, de educación, de crianza, de noviazgo y de matrimonio incuestionables e inamovibles, asumían papeles sexuales asignados en perjuicio del desarrollo pleno de las personas.

En la segunda mitad del siglo XX, los movimientos de liberación femenina socaban, con sus luchas, los papeles sexuales asignados. Manifestaciones públicas, congresos, reuniones locales, nacionales e internacionales sirven de encuentro para que las personas analicen y cuestionen los estereotipos sexistas y las actitudes de la humanidad en general hacia lo que es, y hacia lo que deben ser, los vínculos emocionales entre hombres y mujeres en la convivencia cotidiana.
En esta época histórica surgen voces colectivas e individuales preocupadas por la desigualdad sexual y sus voces cobran protagonismo cuando abogan por una igualdad y equidad de derechos para ambos sexos.

Es así como comienzan a surgir una serie de políticas que legislan sobre igualdad de oportunidades para hombres y mujeres, como medida para visualizar el papel de la mujer en la sociedad y evitar cualquier clase de discriminación sexista.

Sin embargo, ya a fines del siglo XX, un nuevo estereotipo empañaba la armonía de los vínculos emocionales entre hombres y mujeres, al considerarse ahora lo masculino como nefasto, cruel, violento y odioso. Surge también el estereotipo que la mujer no se realiza a plenitud con las labores domésticas, o responsabilizándose de su papel de madre y esposa, y por diferentes medios se capta el mensaje que hace pensar que su realización plena está fuera del hogar.

Nuevamente el camino hacia una convivencia en la que exista el respeto, amor y justicia parece retardar, al surgir la discriminación contra el hombre, promoviendo actitudes excluyentes y revanchistas que conducen a la humanidad a cometer los mismos errores del pasado.

La denuncia y la lucha para evitar la discriminación sexual, tanto de hombres como de mujeres, es el reto de los tiempos, para vivir como seres humanos respetando la diversidad. Surge así el movimiento "Democracia de Género", como consecuencia de una reevaluación mundial de la teoría género, respetuosa de los Derechos Humanos.

García y Barahona (2001), analizan en retrospectiva, los cambios radicales en los papeles sociales que han protagonizado las mujeres en los últimos treinta años del siglo XX, y señalan que estos han significado un avance considerable hacia la equidad de género, pero que falta bastante camino por recorrer y que si bien el cambio de las 
mujeres se muestra como condición necesaria, no es suficiente para el avance. Por lo tanto, consideran que la propuesta "Democracia de Género" viene a enfatizar la necesidad de poner mucho más cuidado en los medios para conseguir los fines y proponer los cambios para la sociedad por una vía democrática, evitando el conflicto de sexos o la tendencia al estancamiento y avanzando siempre, hacia la búsqueda de la equidad.

Gomáris y Meentzen (2000) presentan una serie de estudios que fundamentan esta propuesta para hombres y mujeres del siglo XXI, señalan que la "Democracia de Género" surge en la Alemania de los años noventa, como respuesta al estancamiento en que se encontraban las políticas de igualdad de oportunidades. Una de las características de esta propuesta es su naturaleza género-inclusiva, en el sentido que no se dirige sólo a las mujeres, sino que convoca a toda la sociedad, mujeres y hombres para seguir avanzando hacia la equidad de género. Este énfasis, en la inclusión, es lo que puede permitir una igualdad de derechos y oportunidades, siempre y cuando éstas no discriminen en modo alguno. Este planteamiento propicia también, espacios para reflexionar sobre la construcción de la identidad masculina, las características propias o distorsionadas de género adquiridas durante el proceso de socialización, el repertorio más amplio de oportunidades de comportamiento, la vida emocional y las posibilidades de equilibrar amor y trabajo.

Se puede afirmar que este nuevo paradigma integra las bases para un diálogo fecundo entre hombres y mujeres que avanzan hacia la equidad de género, vista como una corresponsabilidad de ambos. Dentro de la vivencia en una democracia de género, los papeles sexuales los construye, en el contexto sociocultural, cada hombre y cada mujer, según sus características únicas e irrepetibles, sin vivir uno a expensas del otro, sino amándose, compar- tiendo compromisos, responsabilidades, triunfos y fracasos.

La construcción de la feminidad y masculinidad ha sido objeto de numerosos estudios; para Marcela Lagarde (1992) en el lenguaje político de América Latina se proyecta la idea de género ligada sobre todo a las mujeres. Se olvida que cuando se habla de género, se refiere a una cualidad histórica construida no solo para las mujeres, sino también para los hombres. La mayoría de las sociedades ha utilizado la clasificación universal de los géneros para ubicar a los seres humanos y han llegado a pensar que ser mujer o ser hombre es un hecho natural y universal; mas pertenecer al género femenino o al masculino no se adquiere, se construye históricamente. Para Lagarde (1992), las teorías contemporáneas de género consideran que los géneros son grupos biosocioculturales construidos históricamente, a partir de la identificación de las características sexuales de la persona y una vez que se clasifica a la persona se le asigna de manera diferencial, un conjunto de funciones, actividades, relaciones sociales, formas de comportamiento, en fin, papeles sexuales específicos.

El cuerpo sexual femenino o masculino comienza desde la concepción un proceso evolutivo de construcción de su papel sexual asignado históricamente por la cultura de la sociedad donde se nace. Es así como se hace realidad la premisa del enfoque de género, de que la división del trabajo y las relaciones de convivencia entre hombres y mujeres se aprenden, se refuerzan y se sancionan cuando es necesario, y por lo tanto, los papeles sexuales pueden ser transformados.

El núcleo familiar, con su estilo particular de vida, es el lugar donde el niño y la niña experimentan el primer proceso de socialización. Allí es donde la acción interpersonal posibilita el "nosotros" a partir del "yo" y el "él" y se inicia el aprendizaje de lo que significa ser una persona: hombre o mujer. La información y formación 
familiares son fuerzas enriquecedoras y transformadoras que permiten el desarrollo de cada ser humano, como único e irrepetible, sin discriminaciones basadas en sus características anatómicas y fisiológicas. Nacer como persona supone ser tratada como tal, aún antes de nacer, ser esperado y recibido en el seno de la familia con el amor que corresponde. Por esta razón, el aprendizaje de los valores, actitudes, conocimientos y formas de comportamiento sobre la expresión de la sexualidad humana se inicia desde antes del momento de la concepción.

Desde los primeros años, el niño y la niña demandan progresivamente la exploración de la sexualidad humana al expresarla en la convivencia cotidiana. Es en el seno familiar, donde ambos aprenden cómo un hombre debe relacionarse con una mujer y cómo una mujer debe relacionarse con un hombre. Así mismo, es en la familia donde primero se empieza a experimentar la expresión de sexualidad por medio del papel genérico asignado. El simple hecho que los padres se comporten como seres sexuados, respetuosos de sí mismos y entre ellos como totalidades, sin desvalorizaciones sexistas, facilita al niño y a la niña el aprendizaje que contribuirá a orientarlo hacia una expresión inteligente de la sexualidad.

Durante la niñez intermedia y la adolescencia, se inicia la influencia del grupo de iguales, segunda institución clave en la construcción del papel femenino y masculino. Aunque el grupo de iguales está "más allá" de la familia es un laboratorio para la experimentación de la expresión de la sexualidad mediante los papeles sexuales. El grupo de iguales es un grupo de personas de aproximadamente la misma edad, prestigio y madurez, basado en la cooperación y el respeto mutuos, en el que todos sus miembros ocupan una posición similar. No tiene definiciones legales, ni funciones o deberes formales adscritos y en él no todos los adultos son bienvenidos.
En el grupo de iguales se exploran libremente relaciones interpersonales, expresión de emociones, y papeles sexuales por medio del juego, el diálogo y la experimentación no estructurada de toda una gama de actividades, independientes del propio sexo y sin la censura de los adultos. La acción de los unos sobre los otros conlleva a una crítica recíproca y a una objetividad progresiva. Sin embargo, el grupo de iguales, generalmente afianza los valores, actitudes, formas de comportamiento y conocimientos socioculturales. En consecuencia, puede contribuirse también a perpetuar temores, tabúes, prejuicios e ignorancia en torno a la expresión de la sexualidad humana, pues dentro del grupo de iguales la mayor parte del aprendizaje se produce sin la orientación de personas capaces de aclarar científica y humanamente la información que se maneja.

Otros agentes socializadores que ejercen su influencia en la construcción del papel sexual femenino y masculino son los medios de comunicación colectiva y las instituciones religiosas y educativas. Pero, es la persona la que en última instancia construye su identidad sexual, a partir de sus características biológicas y psicológicas en el contexto sociocultural e histórico.

\section{Respuesta sexual y erotismo}

El cuerpo humano está formado por diferentes zonas erógenas, las que al ser estimuladas desencadenan una compleja respuesta nervio-endocrina que a través del sistema sanguíneo (nervios parasimpáticos) produce diversas respuestas sexuales en hombres y mujeres. Conocer y reflexionar sobre la respuesta sexual humana y estar abiertos al aporte de nuevos estudios, evita comportamientos erróneos y llenos de culpa, con el consiguiente desgaste emocional, conformismo y deterioro progresivo de las habilidades emocionales. Cada expresión de la sexualidad es única 
en su totalidad, y vivirla intensamente, con conciencia plena, permite apreciar en lo cotidiano aquello que siempre es diferente y vasto en posibilidades. La respuesta sexual es un camino de desarrollo y conocimiento interior que lleva al encuentro con la otra persona, involucrando todos los aspectos que conforman al ser: emociones, sentimientos amorosos, actitudes, motivaciones y conocimientos que permiten comparar, analizar y asimilar la experiencia, para trascender (Massoni, 1997).

La interrelación de pareja es un proceso de enseñanza y aprendizaje, de convivencia que explora múltiples perspectivas, mediante la comunicación efectiva entre seres humanos para lograr honesta y voluntariamente conocerse cada uno a sí mismo y al otro, en una relación íntima que hace pensar, amar y crear. Es mediante el diálogo que las personas crecen y construyen una sensación de arraigo que promueve el desarrollo sano de dos seres únicos, diferentes, que viven y aman su diversidad de características emocionales e intelectuales. Pero, aunque el amor libera lo mejor que hay en cada cual, hay retos en la vida que constantemente lo ponen a prueba. Vivir juntos y mantener cada uno su autonomía y autoestima es posible solo a traves del diálogo. Es el diálogo el que permite que tanto él como ella, amen mucho y a cada instante, pero sin dejar de ser ellos mismos. Esto incluye vivir intensamente la respuesta sexual, cuando ambos lo decidan voluntariamente, sin culpa y tomando las medidas de protección que requieran.

La respuesta sexual la viven los seres humanos por motivos tanto sanos como insanos (Jourard y Landsman, 1987). La persona puede buscar la respuesta sexual por motivos insanos como son: el deseo de autoafirmarse, el de relajarse o sedarse, como mercancía de intercambio o para demostrar dominio y poder. Las personas sanas al expresar la respuesta sexual se orientan por motivos que les permitan disfrutar plenamente, sin sentimientos de minusvalía, ni de culpa y sin violentar sus valores morales y espirituales.

La sexualidad enfrenta a la pareja que la vive a los retos del disfrute pleno del placer mutuo, sin transgredir los derechos humanos de ninguno de los dos al establecer una relación significativa. A la respuesta sexual se le considera, en nuestra cultura, símbolo del amor y "hacer el amor" es otro motivo sano que impulsa a esta expresión de la sexualidad, por lo tanto, no es de extrañar que sólo en el contexto de una relación amorosa, en la cual ambas personas se sientan libres, admiradas, apreciadas y deseadas, se logre el más intenso de los placeres.

El deseo consciente de concebir hijos, es otro motivo sano que lleva a la pareja a expresar su sexualidad por medio de la respuesta sexual. La pareja puede elegir libremente procrear o no, más en todo momento debe recordar que se es pareja antes que madre o padre, y que el diálogo neutraliza los obstáculos que se oponen al disfrute de una expresión sexual activa y saludable.

La fuerza revolucionaria liberada por Masters y Johnson, al publicar sus estudios de laboratorio sobre la respuesta sexual, permitió a la sociedad aceptar y discutir sobre sexualidad de una manera franca; sin que esta liberación de actitudes implique, necesariamente, la solución a conflictos en la vivencia cotidiana de la sexualidad.

Masters y Johnson (1978), iniciaron en 1954 una investigación sobre la anatomía y la fisiología de la respuesta sexual humana, en el Departamento de Ginecología y Obstetricia de la Escuela de Medicina de la Universidad de Washington. Luego, en 1959, se instituyó un programa de investigación, sobre los problemas de inadecuación sexual humana que continuó en enero de 1964 con el auspicio de "Reproductive Biology Research Foundation". En la década siguiente se fundamentó la anatomía de la respuesta sexual humana y la 
reacción a estímulos sexuales y se observaron y registraron algunas variantes fisiológicas, como la intensidad y duración de las respuestas sexuales individuales. Este programa de investigación se basó en un intenso interrogatorio médico, social y psicológico, realizado a las personas del estudio y a la población en general. Los resultados obtenidos se presentaron para discusión y se sometieron también a análisis estadísticos. Las técnicas de observación directa se utilizaron para descubrir las modificaciones físicas que se desarrollan durante los ciclos de respuesta sexual femenino y masculino.

Los Drs. Masters y Johnson (1978) para dar una idea más concisa de las reacciones fisiológicas, dividen el ciclo de la respuesta sexual en cuatro fases: fase de excitación, fase de meseta, fase de orgasmo y fase de resolución. Una gama de estímulos físicos y psicológicos pueden dar inicio a la fase de excitación; en esta fase aumenta el ritmo cardiorrespiratorio y la presión arterial y se produce un incremento generalizado de la tensión muscular y de la vaso-congestión. Estos signos fisiológicos contribuyen a que los genitales cambien de forma, tratando de favorecer la función reproductora de la respuesta sexual. En el hombre, el pene se endurece y se agranda y los testículos se aproximan más al cuerpo. En la mujer la vagina se lubrica para acogerlo, el clítoris se agranda y se hinchan los labios mayores y menores. La eficacia e intensidad de los estímulos determina la duración de esta fase y junto con la fase de resolución pueden convertirse en las fases mas prolongadas de la respuesta sexual.

Si la estimulación sexual es efectiva y continua, de la fase de excitación se pasa a la fase de meseta. En esta fase de meseta, los cambios fisiológicos se consolidan y el nivel de excitación se intensifica. En la mujer la vaso-congestión de los tejidos vaginales, abulta el tercio externo de la vagina y estrecha su entrada formando lo que se conoce como plataforma orgásmica, el útero se eleva, el clítoris se retrae debajo de su capuchón y se puede producir el rubor sexual, cambio de color en los labios mayores y menores. Al igual que en ella, en el hombre se mantiene la vaso-congestión de la piel, la tensión muscular aumenta y la respiración, junto con la frecuencia cardíaca acelera su ritmo.

De la fase de meseta se pasa a la fase de orgasmo siempre y cuando la excitación sexual continúe. Esta fase se limita en su duración a escasos segundos, durante los cuales la vaso-congestión y miotonía desarrolladas por el estímulo sexual son liberadas. El orgasmo es una reacción fisiológica y subjetiva que se concentra de modo específico en el clítoris, vagina y útero en la mujer, y en el pene, próstata y vesículas seminales en el hombre. Las reacciones que se registran en la mujer durante el orgasmo son muy variadas, mientras que en el hombre tiende a seguir modelos estándares de reacción eyaculatoria con pocas variaciones individuales.

Durante la cuarta fase, llamada fase de resolución, los órganos y tejidos vaso-congestionados regresan a su estado normal. Hay una pérdida involuntaria de tensión y excitabilidad. La frecuencia cardiorrespiratoria y la presión arterial se estabilizan poco a poco. La mujer tiene la posibilidad de volver al estado de orgasmo en cualquier punto de esta fase, mediante la estimulación eficaz. En el hombre, la fase de resolución incluye un espacio de tiempo refractorio, después del cual la reestimulación eficaz a altos niveles de tensión sexual es posible. En términos generales, la posibilidad fisiológica del hombre para responder a la reestimulación es menor que la de la mujer.

Para R. Massoni (1997) el sexo es la energía fundamental de la vida y la respuesta sexual se puede dividir en el antes, durante y el después. Desde el inicio de una relación la pareja debe conocer las investigaciones sobre el placer masculino y femenino y aprender cómo vibra, en particular, 
cada uno de ellos, para intercambiar puntos de vista y experiencias sobre la expresión de la sexualidad, sin pautas machistas que entorpezcan la relación. Es a partir de esta actitud de exploración de ambos que pueden entregarse a estrategias amorosas sin presiones, sin prisas, sin sentimientos perturbadores que les impidan dejarse estar, vivir y disfrutar su intimidad. Profundizar en el antes, fortaleciendo las habilidades intelectuales y emocionales favorece la calidad y el tiempo útil, aumenta el placer durante el ciclo de la respuesta sexual y prepara el contexto para que la mujer logre orgasmos múltiples y prolongados, pues es ella quien requiere vivir una estimulación más prolongada que le permita aumentar su excitación.

El diálogo sexual y un ambiente sin inhibiciones permitirán a la pareja, ampliar su espectro de erotización para incrementar su excitación y estimularse ilimitadamente. Al expresar la sexualidad hay toda una magia en la cual, sentir es un logro, pero percibir y vibrar en el sentir del otro, es un estado superior de conciencia.

El antes y el después repercuten en el disfrute del durante, pues es en ellos que la pareja construye el camino hacia el goce mutuo. El después abre el espacio para evaluar la vivencia, para reconocer las prácticas psicosexuales que dan placer y llegar a sentirlo y finalmente, brindarlo simultáneamente. Dentro y fuera de la escena de la respuesta sexual, el diálogo sexual de la pareja se impone para comunicarse eficazmente y lograr la sabiduría intelectual y emocional que requiere "hacer el amor", responsabilizándose cada uno de su propio orgasmo y descubriendo las vías de su propio placer.

Cabe destacar también que las condiciones del lugar y las circunstancias en las cuales se vive la respuesta sexual, son factores a considerar, para que voluntaria y amorosamente la pareja intercambie caricias y se estimule mutuamente, sin prisa, las zonas erógenas de sus cuerpos, no únicamente los genitales. Llegar a la búsqueda y al deleite en el placer sexual conlleva a la pareja a construir el erotismo, pues la persona nace sensual y sexual, pero se hace erótica al recibir, de quienes la educan, mensajes explícitos y sutiles acerca de sí misma, y al integrar gradualmente estos mensajes con las experiencias táctiles, con las imágenes mentales y con las emociones personales que las acompañan. El erotismo es ese proceso multifacético por el cual el ser humano moldea su capacidad innata de excitación, aprende a intensificarla, la reprime y la expresa, de acuerdo con las exigencias e ideales socioculturales. Es por esto que la pareja debe aprender sobre su erotismo e investigar sus activadores máximos en detalle, para determinar con claridad las condiciones necesarias para lograr la interacción de la excitación sexual con los retos de vivir y amar (Morin, 1997).

En la relación de pareja, el potencial erótico de la persona se debe expresar de manera voluntaria, respetando los derechos humanos de ambos, sus valores morales y espirituales, y sin sentimientos de culpa que perturben la egosintonía, donde cada uno asuma la responsabilidad de proteger su cuerpo de cualquier maltrato, embarazo no deseado, o enfermedad de transmisión sexual. El tiempo y las circunstancias permitirán a la pareja una comunicación eficaz que fortalezca la construcción de espacios para convivir con amor, respeto y compromiso real.

Con el paso de los años, la respuesta sexual de las parejas que cultivan el diálogo evoluciona hacia estados que nunca creyeron posibles, guiados por una actitud abierta, que les permite no caer en estereotipos. La vivencia de la respuesta sexual cambia invariablemente a lo largo de la vida y la "emoción explosiva" y la "urgencia incontenible" dura un par de años, no más. Es un reto para la pareja construir su propia forma de amarse, basados en el conocimiento mutuo, porque el 
secreto para descubrir los placeres de la respuesta sexual, después de los treinta años de edad consiste en saber lo que se puede esperar tanto psicológicamente como fisiológicamente (Glock, 1998).

$\mathrm{El}$ esfuerzo por vivir y crecer juntos, unidos por amor implica respeto, paciencia, compresión y aceptación uno del otro, tal cual son. Esta aceptación de la otra persona no obliga necesariamente, a aprobar toda lo que ella hace, pero sí permite un diálogo fecundo para que surja la negociación, sobre una base de tolerancia y responsabilidad. Entender que el amor es una elección libre y no una necesidad, permite a cada cual amar sin dejar de ser uno mismo.

\section{La reproducción}

La expresión de la sexualidad humana a través de la reproducción es un complejo proceso biopsicosociocultural que conlleva costo, tiempo y riesgo. El ser humano es la única especie siempre lista para disfrutar de la respuesta sexual. El conocimiento de los estudios científicos sobre el funcionamiento de los ciclos reproductivos le permite a las personas tomar la decisión consciente de si desean o no procrear. Igualmente, es conveniente conocer y explorar la anatomía y fisiología del cuerpo para comprender las estructuras que contribuyen a la reproducción y que juegan también un papel importante al vivir la respuesta sexual.

La maduración sexual y la reproducción al igual que el deseo y la respuesta sexual se encuentran de modo primordial bajo el control del cerebro y de las glándulas del sistema endocrino, cuyos productos llamados hormonas son secretadas internamente, de modo directo al torrente sanguíneo. Las hormonas son mensajeros químicos que llevan su información a órganos específicos estableciendo sistemas de retroalimentación. El cerebro del ser humano ejerce una influencia vital sobre las emociones y el comportamiento sexual. La corteza cerebral controla funciones superiores como el pensamiento, la memoria, la cognición y la ideación, permitiendo el ejercicio de un comportamiento voluntario y responsable, así como el disfrute, el placer y el erotismo. El hipotálamo forma parte también del cerebro y libera hormonas que controlan a la hipófisis o pituitaria, la glándula maestra que coordina y controla las funciones de las demás glándulas endocrinas. El hipotálamo funciona como dispositivo biológico de sincronización y al interactuar con el sistema endocrino, vigila y coordina el inicio de la pubertad, los ciclos de fertilidad y el apetito sexual (Mc Cary, 2000).

Los genitales femeninos externos son muy sensibles y complejos, y en su conjunto se conocen como vulva y están delimitados al frente por el monte de venus. La vulva está formada por los labios mayores, los labios menores, el clítoris y la entrada vaginal. Debajo del clítoris se encuentra la entrada de la uretra, un pequeño orificio muy sensible, envuelto por los labios mayores y los labios menores que permite la salida de la orina. A la zona que comprende la entrada de la vagina y la entrada de la uretra se le llama vestíbulo, esta zona es de gran sensibilidad debido a la gran cantidad de terminaciones nerviosas que convergen.

En ambos lados de la entrada vaginal se encuentra la salida de las glándulas de Bartholin, las cuales, durante la excitación sexual segregan gotas de un líquido altamente lubricante, que facilita la penetración del pene. Asimismo, en la entrada de la vagina se encuentra el himen, este tejido raramente cubre la totalidad del orificio externo de la vagina y presenta características diversas según cada mujer. La vagina es un tubo fibromuscular, muy elástico, que mide siete $\mathrm{u}$ ocho centímetros de la vulva a su parte interna. En el tercio externo de la vagina, que es el más sensible (en su cara anterior o frontal) y en relación 
directa con los huesos del pubis, a cinco centímetros de la vulva, se encuentra una zona de alta respuesta erógena llamada "punto G". Este punto está formado por una serie muy compleja de tejidos, glándulas, vasos sanguíneos, conductos parauretrales y una red de terminaciones nerviosas. Una estimulación adecuada en esa zona puede producir orgasmos vaginales $u$ orgasmos del punto $\mathrm{G}$, completamente diferentes a los orgasmos del clítoris (Massoni, 1997).

Los órganos reproductores femeninos se encuentran en la pelvis y son básicamente dos ovarios, el útero y las llamadas trompas de falopio, asimismo la vagina, órgano intermedio previamente descrito. A los ovarios se les denomina también gónadas y se encuentran ubicados a los lados del útero. Sus dos funciones primordiales son la producción de óvulos y la secreción de las hormonas femeninas: estrógenos y progesterona, gracias a la retroalimentación que se produce cuando el hipotálamo ejerce su control biológico produciendo la hormona liberadora de las gonadotropinas que ordena a la hipófisis o pituitaria secretar cuando menos tres hormonas relacionadas directamente con la reproducción: la hormona estimulante del folículo, la luteinizante y la prolactina, que estimula la secreción de leche en las glándulas mamarias, después del parto. Los estrógenos se producen en las gónadas femeninas, por estimulación de la hormona estimulante del folículo y es en esencia una hormona del crecimiento, muy importante para el desarrollo de la estructura corporal de los órganos sexuales y de las características sexuales secundarias.

Durante el ciclo menstrual, los estrógenos ejercen múltiples efectos, entre ellos influir en la producción de la hormona estimulante del folículo y contribuir a que el endometrio se engruese durante la primera mitad del ciclo menstrual. La progesterona se secreta en los ovarios por influencia de la hormona luteinizante.
Además, cuando esta hormona luteinizante alcanza una cierta proporción en relación con la hormona estimulante del folículo, se desencadena la ovulación. La duración del ciclo reproductivo se cuenta del primer día que aparece la menstruación, al primer día anterior a la siguiente. Es común que durante cada ciclo se expulse un solo óvulo de un solo ovario, pero en algunas ocasiones no ocurre así. También puede ocurrir que se produzcan dos ovulaciones en un ciclo y que una de ellas suceda durante la menstruación (Massoni y Mc Cary, 2000).

Las trompas de falopio son dos conductos que transportan al óvulo desde el ovario hasta el útero. El útero tiene forma de pera y es un órgano de paredes musculosas, cuya longitud es aproximadamente de ocho centímetros y consta de dos porciones: la superior o cuerpo y la inferior o cerviz. El cuerpo del útero es mucho más grande que la cerviz y durante el embarazo un tapón mucoso cierra el orificio externo de la cerviz creando una verdadera muralla entre la vagina y el útero, protegiendo asimismo el óvulo fecundado (Massoni, 1997).

Los órganos sexuales pélvicos masculinos están formados por dos testículos o gónadas, localizadas fuera de la cavidad del cuerpo, en un saco de piel llamado escroto y el pene. El pene está formado por el glande o cabeza del pene, zona de mayor sensibilidad, donde se localizan infinidad de terminaciones nerviosas. El glande se une con el tallo del pene mediante una formación llamada corona. En la parte extrema del pene está la apertura de la uretra, la cual transporta tanto la orina como los espermatozoides.

El tallo del pene se encuentra cubierto por una piel muy elástica, distensible y laxa que se prolonga hacia la piel del escroto que permite la erección cuando, durante la fase de excitación, la sangre fluye más o menos rápidamente y llena los cuerpos cavernosos y el tejido esponjoso. En la parte interna de los testículos se producen 
los espermatozoides. Allí existen aproximadamente mil túbulos seminíferos enrollados en los que se producen millones de espermatozoides.

En el hombre, durante la pubertad, las hormonas liberadas por la hipófisis o pituitaria, ante la orden del hipotálamo, ejercen su influencia sobre las gónadas para que se genere la espermatogénesis. La hormona luteinizante es la que estimula y da mantenimiento a las células intersticiales (diseminadas alrededor de los túbulos seminíferos) para que produzcan andrógenos, hormonas masculinas, dentro de las cuales se aloja la testosterona, responsable del desarrollo y preservación de las características sexuales secundarias como son: el vello facial y corporal, cambio de voz, desarrollo, tamaño y función de los órganos sexuales secundarios (vesículas seminales, próstata, pene y escroto). La hormona estimulante del folículo actúa también estimulando los túbulos seminíferos y junto con la testosterona, producen el desarrollo de espermatozoides. Las hormonas andrógenas y estrógenos se producen tanto en hombres como en mujeres, pero es importante recalcar que la respuesta sexual humana está más influenciada por factores emocionales y físicos que por la actividad hormonal (Mc Cary, 2000).

Los espermatozoides, casi maduros, pasan desde el testículo hacia el epidídimo que es un abultamiento insertado en cada testículo, formado por una serie de tubos enroscados, donde se almacenan los espermatozoides hasta completar su desarrollo y crecimiento. El epidídimo se conecta con la uretra a través de un tubo largo, denominado conducto deferente. En el momento de la eyaculación las vesículas seminales, la próstata y las glándulas de Cowper aportan lo que se conoce como líquido seminal, medio que contribuye al transporte de espermatozoides y que en conjunto con ellos, forman el semen.

La fertilización ocurre cuando una de las células germinales masculinas o espermatozoides se unen con una célula germinal femenina u óvulo, para crear una sola célula a partir de la cual se desarrolla un nuevo ser. El espermatozoide y el óvulo son las únicas células del cuerpo humano que contienen 23 cromosomas cada una. Los 22 cromosomas no sexuales más el cromosoma determinante del sexo del espermatozoide se unen con los 22 cromosomas más el cromosoma determinante del sexo del óvulo, para dar origen a un huevo fertilizado o cigoto con 46 cromosomas.

La vida prenatal se divide en tres etapas: a) período ovular; cuya duración se enmarca en una semana a partir de la fertilización, b) período embrionario; que se prolonga de la segunda semana a la octava semana de gestación y c) período fetal; comprendido entre el tercer mes y el nacimiento (Mc Cary, 2000).

A partir del momento de la fertilización la persona es protagonista de la primera gran historia. El profesor francés Jerome Lejeume, biólogo y genetista de reputación mundial (1977), afirma que en esa primera célula, surgida del proceso de fecundación, se encuentran todas las cualidades genéticas del ser humano y que siete días después de la fecundación, ese ser mide ya un milímetro y medio y emite un mensaje químico que "fuerza" a la madre a conservarlo.

Este ser único, continúa Lejeume (1977), vive en el útero en un ambiente agradable que le proporciona elementos para su crecimiento y desarrollo, flota libremente en el líquido amniótico y es acunado por los movimientos maternales. A los veinte días tiene el tamaño de un grano de trigo, su corazón empieza a palpitar y se esbozan sus diminutos miembros. Cuando cumple los dos meses es tan pequeño que cabe en la cáscara de una nuez. Asume apariencia humana: tiene cara; incluyendo las estructuras externas de los ojos, nariz y orejas, boca, extremidades reconocibles, dedos en los pies y en las manos, incluso las líneas de éstas. Empieza a ser capaz de responder por primera vez, a los cambios producidos en el ambiente en el cual está evolucionando, a veces con fuertes "movimientos protectores". 
Al cumplir tres meses tiene sus minúsculas huellas digitales perfectamente trazadas. Si pudiera colocarse en la palma de una mano podría verse fácilmente y haría una mueca si se le acaricia el labio superior con un hilo, es capaz de cerrar los ojos y las manos, ha desarrollado sus músculos y órganos sexuales. Traga grandes cantidades de líquido amniótico porque le gusta muchísimo. Se nota por primera vez el comportamiento espontáneo, inicio de una actividad que parece nacer del interior de su organismo.

Al final del cuarto mes puede abrir y cerrar su boca y manos. Sigue desarrollando la eficacia de sus repuestas para lograr "resultados", reaccionando a su ambiente con muestras de inteligencia cognitiva y emocional. Desde el comienzo del quinto mes de su vida van apareciendo gradualmente, en él o ella, las diversas formas de comportamiento que se observan durante sus primeros días de existencia aeróbica.

Después del sexto mes es capaz de respirar, puede detectar los ruidos intestinales, chasquidos articulares, el rítmico sonido del corazón materno, las voces familiares y la música del mundo exterior. Durante los últimos meses continúa su proceso de maduración, con el aumento paulatino de sus posibilidades de supervivencia.

Al nacer, la propia experiencia del parto tiene un efecto profundo sobre el ser humano. El bebé o la bebé deben respirar por sí mismos y tendrán que adaptarse rápidamente a un nuevo mundo para sobrevivir. Ahora la madre y el padre acarician al recién nacido y le dan la bienvenida, es este el momento mágico, propicio para formar fuertes vínculos emocionales en la familia.

\section{Educación de la expresión de la sexualidad}

Desafiante y placentero es construir ambientes de enseñanza y aprendizaje para la educación de la expresión de la sexualidad, enfatizando la trascendencia del papel que juega la inteligencia emocional en el proceso. Existen suficientes investigaciones que respaldan la necesidad de fortalecer los esfuerzos que se realizan para educar la expresión de la sexualidad de los niños, niñas y adolescentes. En las escuelas se favorecen, fundamentalmente, las habilidades propias de la inteligencia lingüística y lógico-matemática, y se pospone estimular sistemáticamente las habilidades propias de la inteligencia emocional.

Dentro de las habilidades de la inteligencia emocional se encuentran las habilidades propias de las inteligencias intrapersonal e interpersonal. Este conjunto de habilidades: autoconocimiento, autocontrol, automotivación, empatía y relaciones sociales son fundamentales para una expresión de la sexualidad emocionalmente inteligente. Cuando la persona se conoce a sí misma, aprende a autocontrolarse, disfruta de lo que hace y se coloca en el lugar de los otros sin dejar de ser ella misma, establece relaciones de convivencia que le permiten mantener su autonomía y su autoestima y equilibra, con mayor propiedad, trabajo y amor.

Otro pilar fundamental de la educación de expresión de la sexualidad es la adquisición de conceptos pertinentes que permitan conocer, analizar y valorar el funcionamiento pleno del ser humano como ser sexuado. En el tiempo actual, las investigaciones sobre la expresión de la sexualidad humana en los vínculos afectivos, en el papel sexual, en la respuesta sexual y en la reproducción, son numerosas y bien fundamentadas. Con enorme rapidez, la información se actualiza y se aportan a la Humanidad nuevos elementos para que la persona enriquezca su estructura cognoscitiva en el área de la sexualidad y construya y reconstruya, la expresión de la misma.

El tercer pilar fundamental en la educación de la expresión de sexualidad son las características del educador y de la 
educadora, sea este padre, madre, maestro o maestra. La institución educativa y la familia deben ser coherentes y establecer, en forma coordinada, lineamientos claros y flexibles para educar la expresión de la sexualidad de niños, niñas y adolescentes.

Los retos o desafíos que enfrenta el educador o la educadora son múltiples, complejos, diversos y singulares. Pero, es él o ella con sus características propias y únicas quien pone su sello, agiliza o bloquea el proceso, lo enriquece al permitir la construcción de posiciones y de estrategias, o lo empobrece al manipular y perpetuar ignorancias.

\section{Principios orientadores de la educación de la expresión de la sexualidad humana}

1. Centrar los procesos de enseñanza y de aprendizaje en las características y necesidades biológicas, sociales y espirituales de las personas participantes.

2. Propiciar la vivencia de un proceso de participación, discernimiento y diálogo que permita a la persona analizar sus mitos, prejuicios, tabúes, conocimientos, actitudes y valores en torno a la sexualidad humana.

3. Facilitar la búsqueda, procesamiento y almacenaje eficiente de investigaciones científicas, con miras al logro de aprendizajes significativos.

4. Mediar para que las personas construyan habilidades cognitivas y habilidades emocionales que les permitan expresar, en forma inteligente, su sexualidad.

5. Promover un proceso altamente comunicativo que permita la expresión de la diversidad y la autenticidad de cada persona.
6. Contextualizar el derecho de los seres humanos a asumir el disfrute libre y responsable de la sexualidad dentro del amor, guiado por sus principios y valores, dentro de un marco de derechos humanos.

Los principios orientadores descritos se fundamentan en la concepción de la persona como un ser único, irrepetible e inacabado, en continuo proceso de aprendizaje y de desarrollo; y que los procesos de enseñanza y de aprendizaje de la sexualidad se tienen que vivir en un ambiente democrático, humanizado, donde las relaciones interpersonales fortalezcan una comunicación eficiente.

Los adultos significativos para los niños, niñas y adolescentes, tienen que unificar conocimientos, posiciones y evitar los comentarios contraproducentes que demuestren incomprensión de la expresión de la sexualidad y destruyan la confianza. Debe evitar cualquier valoración o diagnóstico que interfiera en el logro de relaciones interpersonales armoniosas.

Los padres y los maestros unidos, informando y formando sobre expresión de la sexualidad pueden contribuir, con sus actitudes sanas, a desterrar los dogmas, las inquisiciones, las ignorancias y los fanatismos de toda clase acerca de la sexualidad humana que han enardecido el vuelo del espíritu crítico, sobre todo, para aquellas personas que tienen el valor de disentir de sus semejantes. Nunca es tarde para crear una apertura que deje pasar las nuevas ideas. Admitir la verdad que hay en las concepciones ajenas, elaborar las propias y tener criterio independiente requiere de un sentido universal, apartado del estrecho y limitado que se forma cuando se vive en una ínsula sin posibilidades de construir y reconstruir posiciones. Solo un educador y una educadora que conozcan y acepten a plenitud su naturaleza humana de personas sexuadas podrá orientar verdaderos y satisfactorios procesos de enseñanza y de aprendizaje de la sexualidad. 
El educador y la educadora deben promover la formación de personas que expresen su sexualidad en forma inteligente, cognitiva y emocional. La educación de la expresión de sexualidad comienza desde antes de la concepción misma del nuevo ser, desde el momento en que la pareja decide que quiere ser papá y mamá. La maternidad y la paternidad deben fundarse en decisiones voluntarias y responsables.

El niño y la niña en edad preescolar necesitan aprender sobre expresión de sexualidad en forma natural. En esta edad los patrones de convivencia familiar orientan la mayoría de sus formas de comportamiento. El hogar se convierte en el primer laboratorio de educación de expresión de la sexualidad, donde el niño y la niña aprenden cómo un hombre y una mujer conviven, los adultos consciente o inconscientemente son ejemplos vivientes con sus actos cotidianos. Los padres de familia tienen que tener claro que primero se es pareja y después padre y madre, y por lo tanto, les corresponde a ellos clarificar y fortalecer sus actitudes, valores y conocimientos de su propia expresión de la sexualidad para sistematizar conscientemente una serie de acciones para la educación de la expresión de sexualidad de sus hijos e hijas.

Dentro de estos procesos de enseñanza y aprendizaje de la expresión de la sexualidad, en edad preescolar, los actos dicen más que las palabras. El lenguaje es esencial para que el pequeño y la pequeña vayan construyendo su esquema corporal, dando a cada parte del cuerpo el nombre correcto; dentro de este vocabulario hay que incluir los nombres exactos de los genitales femeninos y masculinos. Así mismo, las preguntas de los niños y las niñas sobre sexualidad se tienen que responder en forma clara y sencilla, con respuestas centradas en los intereses y necesidades de estas personitas, de tal forma que el diálogo quede abierto para retomarse en cualquier momento pertinente. Preguntar y repreguntar, van a permitir al niño y a la niña construir conceptos y acciones en torno a la expresión de sexualidad y fortalecer sus habilidades, propias de la inteligencia emocional.

A partir de los 7 años, más o menos, el niño y la niña tienen una noción de la permanencia de su sexo y del papel femenino o masculino aceptado por la sociedad en que viven, factores muy importantes para el desarrollo del concepto de sí mismo.

El desarrollo del pensamiento lógico de este niño y de esta niña, les permiten hacer comparaciones entre la forma que diferentes papás y mamás se relacionan, los papeles sexuales que asumen y las formas en que se autocontrolan al resolver conflictos. Además, a partir de los 7 años, mediante el juego y el trabajo en grupo, el niño y la niña aprenden a fortalecer sus habilidades para expresar sentimientos, tomar y expresar una posición personal, aunque en algunas ocasiones les cueste reconstruirla, a partir de los aportes del otro u otra. Así mismo pueden seguir instrucciones y aceptar las normas que se establecen, habilidades que fortalecen su inteligencia emocional y que contribuyen a que se sientan fuertes y seguros, capaces de convivir en armonía, respetando sus derechos y los de los demás.

El educador y la educadora, con conocimiento de cada niño y niña, aceptando la diversidad de diferencias individuales, buscan la forma de incentivar procesos para la adquisición de conocimientos y la aclaración de mitos, prejuicios y tabúes, con miras a que, sin imponer sus puntos de vista, cada persona construya una expresión de la sexualidad inteligente cognitiva y emocionalmente.

Asumir la educación de la expresión de la sexualidad de adolescentes, es quizá el reto mayor que asumen los adultos significativos, deseosos de que las nuevas generaciones disfruten de una expresión de la sexualidad armoniosa, respetuosa y responsable. Ante los rápidos cambios de la 
época, es una labor no de un instante, sino de toda la vida, que se ajusta al desarrollo del adolescente y de la adolescente. No es ético despojar a los adolescentes y las adolescentes de sus derechos y obligaciones recién descubiertos y legitimizados. Por este motivo es conveniente que estas personas se eduquen en un ambiente democrático, donde con toda libertad expresen sus puntos de vista, sus dudas y comentarios en torno a la expresión de la sexualidad. Hoy día el adolescente y la adolescente, por un lado disponen de mayores oportunidades de intimidad, y por otro, son bombardeados por una gran cantidad de estímulos erotizantes que promueven el riesgo de vivir una expresión de la sexualidad que rompa con su opción de construir y reconstruir su existencia voluntariamente.

Con base en el planteamiento anterior, es pertinente que los adultos significativos abran espacios para que grupos de adolescentes, discutan en su compañía, dilemas sexuales de interés para ellos y ellas, que les permitan expresar sus opiniones y construir y reconstruir sus posiciones, así como expresarlas y defenderlas públicamente. Con este dialogar y discutir él y ella van fortaleciendo la construcción de su escala de valores y su filosofía de la vida, fundamento que respaldará la expresión de su sexualidad en la convivencia cotidiana.

\section{A manera de conclusión}

Quebrantar la ley del silencio mediante procesos de enseñanza y de aprendizaje que fortalezcan una expresión de la sexualidad inteligente, cognitiva y emocionalmente, es la tarea de educadores y educadoras que velan por la salud psicológica, biológica, espiritual y social de las generaciones venideras. Y es aquí donde la persona adulta se enfrenta al dilema de cómo resolver sus propios conflictos sobre expresión de la sexualidad y transmitir actitudes sanas, libres de mitos, tabúes y prejuicios, sin adoctrinar a los seres humanos que educa.
Como explica el informe escrito por Delors (1996), es la educación durante toda la vida, la que permite una reestructuración continua de la persona, de su conocimiento, de sus actitudes, de su facultad de juicio y acción para responder de manera flexible y diversa a los retos del mundo en el tiempo y en el espacio. La educación encierra un tesoro y sus alcances llevan a aprender a vivir juntos, a aprender a conocer, a aprender a hacer y a aprender a ser.

Por tanto la educación permanente de los educadores y las educadoras, en la expresión de la sexualidad, les permite tomar conciencia de sí mismos, lo que indudablemente mejora su quehacer, y además les facilita una mayor empatía y un respeto por los tiempos de reacción, los silencios reflexivos y la construcción única de expresión de la sexualidad de los niños y las niñas, las adolescentes y los adolescentes. En otras palabras, se abrirá el camino hacia un auténtico diálogo, bien fundamentado, sin respuestas prefabricadas.

Son las personas adultas las que, con formación e información siempre actualizada, acortan la brecha generacional al emplear un lenguaje común y al expresar su propia sexualidad, sin romper su egosintonía, voluntariamente y con responsabilidad médica, dentro del marco de los derechos humanos.

Como invitación final a la discusión y al diálogo se presentan a continuación los cuatro grandes objetivos generales de la educación de la expresión de la sexualidad que se tiene que ajustar siempre al diagnóstico previo que el educador y la educadora realizan antes de iniciar los procesos de enseñanza y aprendizaje:

Generar una actitud libre de mitos, prejuicios y tabúes hacia la sexualidad humana.

Construir formas inteligentes, cognitiva y emocionalmente, de expresar la sexualidad dentro del amor.

Analizar conocimientos pertinentes y actualizados que contribuyan a la adopción 
de un código ético, que respalde la expresión de la sexualidad dentro del marco de los derechos humanos.

Asumir el disfrute pleno y voluntario de la sexualidad, sin romper la egosintonía, y con protección médica.

\section{Referencias bibliográficas}

Carballo, Sonia. Intervenciones para ayudar a construir la inteligencia emocional. Educación 22(1): 77-89, San José, 1998.

Delors, Jacques. La educación encierra un tesoro. Santillana. Ediciones UNESCO. Madrid. 1996.

Erikson, Erik. Infancia y Sociedad. Editorial Hoemé, Buenos Aires, 1970.

García, Ana Isabel y Barahona, Manuel. "Democracia de Género" en: La Nación, San José, 1997.

Glock, Alison. Viva plenamente la sexualidad después de los 30. Selecciones Readers Digest. México DF. Abril, 1998.

Gomáriz, Enrique y Meentzen, Ángela. Democracia de Género: una propuesta para mujeres y hombres del siglo XX, Antología. San José,
Fundación Género y Sociedad(GESO), 2000.

Havighurst, Robert. Human development and education. New York. Longmans, Green, 1953.

Jourard, Sindney y Landsman Ted. La Personalidad Saludable. Trillas. México DF. 1987.

Lagarde, Marcela. Identidad de Género. Material ofrecido por la Dra. Lagarde. Managua, 1992.

Lejeume, Jerome. Abortar es matar. aunque el cadáver sea muy pequeño. Revista Tiempo Actual, número 5. San José, 1977.

Morín, Jack. La Mente Erótica. Ediciones Aguilar. México, 1997.

Massoni, Reinaldo. Sexo: energía fundamental de la vida. Editorial Aguilar, Atea, Taurus, Alfaguara S.A. México DF. 2000.

Masters, William y Johnson, Virginia. La Respuesta sexual humana. Editorial Inter-Médica. Buenos Aires, 1978.

Mc Cary, James y otros. Sexualidad Humana. Editorial El Manual Moderno. México DF. 2000.

Sonia Carballo Vargas

Profesora de la Escuela de Formación Docente de la Universidad de Costa Rica 